\title{
Hubungan Durasi Mengetik Komputer dan Posisi Mengetik Komputer dengan Gejala Carpal Tunnel Syndrome (CTS) pada Karyawan Universitas Islam Bandung
}

\author{
Triana Nur Aripin, ${ }^{1}$ Adjat Rasjad, ${ }^{2}$ Nurdjaman Nurimaba, ${ }^{3}$ \\ M. Ahmad Djojosugito, ${ }^{4}$ Siska Nia Irasanti ${ }^{5}$ \\ ${ }^{1}$ Program Studi Pendidikan Dokter, ${ }^{2}$ Departemen Neurologi, ${ }^{3}$ Departemen Fisiologi, \\ ${ }^{4}$ Departemen Ortopedi, ${ }^{5}$ Departemen Ilmu Kesehatan Masyarakat, \\ Fakultas Kedokteran, Universitas islam Bandung
}

\begin{abstract}
Abstrak
Penggunaan komputer dalam bekerja meningkat pesat baik dalam bidang industri maupun bidang pekerjaan lainnya. Penggunaan komputer dalam bekerja meliputi posisi mengetik dan durasi penggunaan komputer. Aktivitas mengetik dalam durasi yang lama dan posisi yang salah saat mengetik dapat berisiko terkena penyakit pada jari tangan dan pergelangan tangan. Tujuan penelitian ini mengetahui hubungan durasi dan posisi mengetik komputer dengan gejala carpal tunnel syndrome (CTS) pada karyawan Universitas Islam Bandung. Penelitian ini menggunakan pendekatan potong lintang. Populasi dalam penelitian ini adalah karyawan Universitas Islam Bandung. Instrumen penelitian yang digunakan berupa kuesioner. Responden penelitian berjumlah 54 orang yang sudah memenuhi kriteria inklusi. Data dianalisis dengan uji chi-square dan Uji Eksak Fisher. Hasil penelitian memperlihatkan bahwa tidak terdapat hubungan yang signifikan antara durasi mengetik komputer dan gejala carpal tunnel syndrome $(\mathrm{p}=\mathrm{O}, 75)$, terdapat hubungan yang signifikan antara posisi mengetik komputer $(\mathrm{p}=\mathrm{O}, \mathrm{07})$ dan gejala carpal tunnel syndrome. Dari 54 responden, 32 responden memiliki gejala carpal tunnel syndrome.
\end{abstract}

Kata kunci: Carpal tunnel syndrome, durasi mengetik komputer, posisi mengetik komputer

\section{The Relationship of Computer Typing Duration and Computer Typing Position with Symptom of Carpal Tunnel Syndrome among Employees of Bandung Islamic University}

\begin{abstract}
The use of computer in work increase rapidly in industry field or another field of work. The use of computer in work consist of the position and the duration of using computer. Typing activity in long duration and with wrong position could become the risk factor of finger and wrist disease. This research was conducted to assess the relationship of computer typing duration and computer typing position with symptom of carpal tunnel syndrome. This research used the approach of cross sectional. The population in this research was employees of Bandung Islamic University Research Instrument in the form of questionnaires. Total of samples were 54 respondents that already fulfill the inclusion factors. Data were analyzed by chi-square test and Fisher-exact test. The research found that there was no significant relationship between computer typing duration $(\mathrm{p}=0.75)$ and the symptom of carpal tunnel syndrome and there was significant relationship between and computer typing position $(\mathrm{p}=0.08)$ and the symptom of carpal tunnel syndrome. From the 54 respondents, 32 respondents had the symptoms of carpal tunnel syndrome.
\end{abstract}

Keywords: Carpal tunnel syndrome, computer typing duration, computer typing position 


\section{Pendahuluan}

Pertumbuhan industri dan pertambahan tenaga kerja menimbulkan berbagai dampak positif dan dampak negatif. Salah satu dampak negatifnya adalah peningkatan penyakit akibat kerja. International Labour Organization (ILO) tahun 2013 menyatakan satu pekerja di dunia meninggal setiap 15 detik karena kecelakaan kerja dan 160 pekerja mengalami sakit akibat kerja. ${ }^{1}$

Studi dari Departemen Kesehatan dalam profil masalah kesehatan di Indonesia telah menunjukkan bahwa sekitar $40 \%$ penyakit yang diderita pekerja berhubungan dengan pekerjaan dan angka tertinggi diraih oleh gangguan muskuloskeletal sekitar $16 \%{ }^{2}$

Salah satu gangguan muskuloskeletal itu dikenal dengan istilah cumulative trauma disorder (CTD). CDT adalah cidera muskuloskeletal dan sistem saraf yang disebabkan oleh pekerjaan yang berulang, pengerahan tenaga yang terlalu kuat, getaran, kompresi mekanik, ataupun akibat posisi yang salah saat beraktivitas. ${ }^{3}$

Carpal tunnel syndrome (CTS) merupakan sindrom yang timbul akibat tekanan neuropati terhadap saraf medianus dalam terowongan karpal pada pergelangan tangan yang tepatnya di bawah fleksor retinakulum. ${ }^{4}$

Faktor yang menjadi risiko terjadi CTS pada pekerja, yaitu gerakan yang berulang pada tangan, mengetuk serta fleksi dan ekstensi yang berulangulang seperti mengetik komputer. Keadaan tersebut merupakan salah satu faktor paling besar yang dapat mengakibatkan CTS dan didukung dengan perkembangan teknologi yang sangat maju menuntut para perkerja sering menggunakan komputer untuk membantu memudahkan pekerjaan. tetapi sebaliknya pengetahuan pekerja mengenai pencegahan penyakit akibatkerja dalam penggunaan komputertidakcukup..$^{5,6}$

Angka kejadian CTS di Amerika Serikat telah diperkirakan sekitar 50 kasus dari 1.000 orang pada populasi umum. Prevalensi CTS di Indonesia dalam masalah kerja belum diketahui karena sangat sedikit diagnosis penyakit diakibatkan kerja yang dilaporkan. ${ }^{7}$

Penelitian Tanaka dkk. ${ }^{5}$ dinyatakan bahwa jumlah tenaga kerja dengan CTS di beberapa perusahaan garmen di Jakarta sebanyak 20,3\% responden dengan besar gerakan biomekanik berulang. Berbeda dengan penelitian sebelumnya American Medical Association yang menyimpulkan bahwa durasi mengetik komputer tidak berhubungan dengan gejala CTS karena didapatkan hanya $5 \%$ pekerja yang mengalami gejala CTS dari 5.600 pekerja perusahaan yang menggunakan komputer.

Carpal tunnel syndrome dapat menimbulkan kecacatan pada pekerja, seperti membatasi fungsifungsi pada pergelangan tangan dan tangan sehingga berpengaruh terhadap pekerjaan sehari-hari. Di pihak pengusaha menimbulkan kerugian akibat penurunan produktivitas, serta pengeluaran yang meningkat dalam bentuk biaya pengobatan dan pembayaran untuk ganti rugi karena keterbatasan dan kecacatan pekerja. ${ }^{9}$

Peneliti tertarik meneliti hal tersebut karena penelitian tentang CTS masih terbilang sedikit di Indonesia dan khususnya di Kota Bandung. Peneliti juga bermaksud memberikan informasi mengenai pentingnya tentang pelaksanaan keselamatan dan kesehatan kerja (K3) dalam bekerja khususnya pada karyawan Universitas Islam Bandung (Unisba) agar dapat terbentuk lingkungan kerja yang sehat.

\section{Metode}

Penelitian ini menggunakan metode analitik dengan pendekatan cross sectional mengenai hubungan durasi mengetik komputer dan posisi mengetik komputer dengan gejala carpal tunnel syndrome pada karyawan Universitas Islam Bandung.

Subjek penelitian adalah karyawan Universitas Islam Bandung (Unisba) yang sudah memenuhi kriteria inklusi, yaitu karyawan yang menggunakan komputer saat bekerja, minimal bekerja 1 tahun, karyawan laki-laki ataupun perempuan dan bersedia menjadi responden pada penelitian ini. Kriteria eksklusi adalah responden dengan riwayat trauma seperti dislokasi, fraktur pada jari tangan, pergelangan tangan, memiliki diabetes melitus, reumatik, dan sedang hamil. Jumlah sampel pada penelitian ini adalah 54 orang dengan menggunakan teknik pemilihan sampel consecutive random sampling menggunakan kuesioner. Analisis data dilakukan dengan analisis bivariat menggunakan uji chi square dan Uji Fisher dengan program SPSS for windows.



Benar

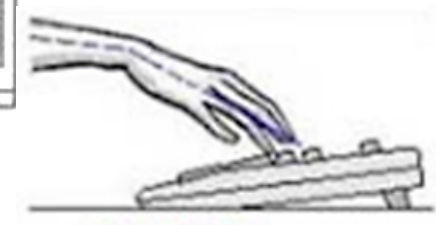

Salah

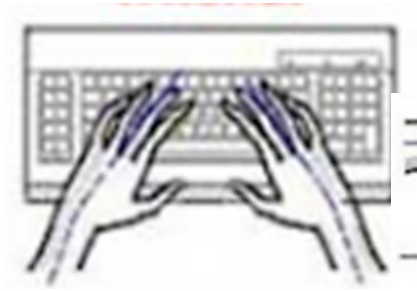

Salah

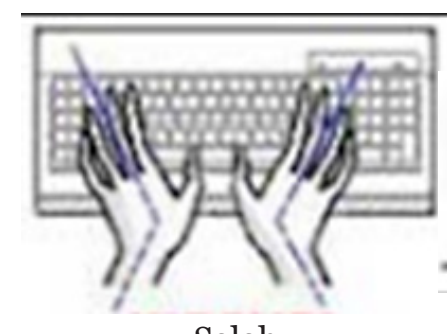

Salah

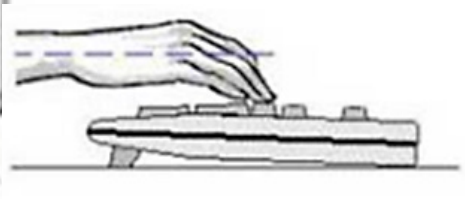

Benar

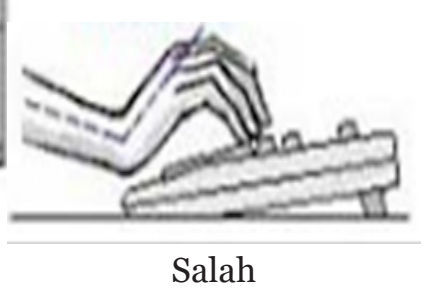

\section{Gambar 1 Posisi Tangan yang Ergonomis}

Penelitian ini sudah mendapat persetujuan etik oleh Komite Etik Penelitian Kesehatan Fakultas Kedokteran Universitas Islam Bandung dengan Nomor: 187/ Komite Etik.FK/III/2018. Aspek penelitian ini memiliki 4 prinsip, yaitu respect for person, autonomy, non maleficence, dan justice. 
Tabel 1 Kuesioner Penelitian

\begin{tabular}{|c|c|}
\hline Kuesioner Penelitian & Pilihan Jawaban \\
\hline $\begin{array}{l}\text { Gejala CTS* } \\
\text { 1. Keparahan rasa nyeri pada tangan/pergelangan tangan } \\
\text { saat malam hari. } \\
\text { 2. Nyeri pada tangan/pergelangan tangan membuat } \\
\text { terbangun saat malam hari. } \\
\text { 3. Nyeri pada tangan/pergelangan tangan pada saat bekerja. } \\
\text { 4. Seberapa sering nyeri pada tangan/pergelangan tangan } \\
\text { saat bekerja. } \\
\text { 5. Lama nyeri timbul saat bekerja. } \\
\text { 6. Rasa baal pada tangan. } \\
\text { 7. Rasa lemah pada tangan. } \\
\text { 8. Rasa kesemutan pada tangan. } \\
\text { 9. Keparahan rasa baal atau kesemutan pada malam hari. } \\
\text { 10. Rasa kesemutan dan baal membuat terbangun saat } \\
\text { malam hari. } \\
\text { 11. Kesulitan dalam menggengam dan memegang benda } \\
\text { seperti kunci atau pulpen. }\end{array}$ & $\begin{array}{l}\text { Soal No: } 1,3,6,7,8,9 \\
\text { 1. Tidak ada } \\
\text { 2. Sedikit } \\
\text { 3. Sedang } \\
\text { 4. Parah } \\
\text { 5. Sangat serius } \\
\text { Soal No: 2, 4, 10 } \\
\text { 1. Tidak pernah } \\
\text { 2. Sesekali } \\
\text { 3. 2-3 kali } \\
\text { 4 4-5 kali } \\
\text { 5. Lebih dari } 5 \text { kali } \\
\text { Soal No: } 5 \\
\text { 1. Tidak Pernah } \\
\text { 2. Kurang dari 10 menit } \\
\text { 3. 10-60 menit } \\
\text { 4. Lebih dari 1 jam } \\
\text { 5. Berlangsung terus-menerus } \\
\text { Soal No: 11 } \\
\text { 1. Tidak ada kesulitan } \\
\text { 2. Sesekali kesulitan } \\
\text { 3. Agak kesulitan } \\
\text { 4. Kesulitan } \\
\text { 5. Sangat kesulitan }\end{array}$ \\
\hline $\begin{array}{l}\text { Durasi Mengetik } \\
\text { Durasi terlama mengetik komputer dalam } 1 \text { hari bekerja } \\
\text { tanpa istirahat. }\end{array}$ & $\begin{array}{l}\text { 1. Sebentar ( } \leq 55 \text { menit }) \\
\text { 2. Lama (>55 menit) }\end{array}$ \\
\hline $\begin{array}{l}\text { Posisi Mengetik }{ }^{* *} \\
\text { Posisi saat mengetik komputer. }\end{array}$ & $\begin{array}{l}\text { 1. Benar } \\
\text { 2. Salah }\end{array}$ \\
\hline
\end{tabular}

Keterangan:

* Boston Carpal Tunnel Syndrome Questionnaire (BCTQ)10

**posisi mengetik komputer yang digunakan sesuai ILO1

\section{Hasil Penelitian}

Sebagian besar responden memiliki gejala CTS, yaitu sebanyak 32 responden (59\%). Hasil penelitian ini juga menunjukkan sebagian besar responden memiliki durasi mengetik lama sebanyak 33 responden.

Tidak terdapat hubungan yang signifikan antara durasi mengetik komputer dan gejala CTS pada karyawan Universitas Islam Bandung ( $\mathrm{p}=0,75$; Tabel 2)

Sebagian besar responden memiliki posisi mengetik benar sebayak 40 responden (74\%).

Terdapat hubungan yang signifikan antara posisi mengetik komputer dan gejala CTS pada karyawan Universitas Islam Bandung ( $\mathrm{p}=0,08$; Tabel 3).

\section{Pembahasan}

Carpal tunnel syndrome (CTS) adalah penyakit yang mengenai saraf medianus. ${ }^{4}$ Faktor risiko CTS terdiri atas faktor internal dan eksternal. Faktor internal itu meliputi usia, jenis kelamin, obesitas, kehamilan, herediter, menopause, dan kondisi medis lainya. Faktor eksternal yag dimaksud adalah faktor pekerjaan meliputi pergerakan fleksi pada tangan dan pergelangan tangan secara berulang, posisi bekerja yang statis dan tidak ergonimis, durasi bekerja yang terlalu lama, dan pajanan tekanan/beban saat bekerja. ${ }^{11}$ Carpal tunnel syndrome (CTS) memiliki gejala seperti paraestesia (kesemutan), kebas (mati rasa), serta rasa nyeri pada jari tangan pertama, kedua, dan ketiga. Gejala nyeri yang dirasakan lebih berat pada malam hari (gejala nokturnal). ${ }^{4}$ 
Tabel 2 Hubungan Durasi Mengetik Komputer dengan Gejala CTS

\begin{tabular}{lccccc}
\hline \multirow{2}{*}{ Durasi Mengetik } & \multicolumn{2}{c}{ Gejala CTS } & & \multirow{2}{*}{ Total } & p \\
\cline { 2 - 3 } & $\begin{array}{c}\text { Tidak Ada Gejala } \\
\mathbf{n = 2 2}\end{array}$ & $\begin{array}{c}\text { Ada Gejala } \\
\mathbf{n = 3 2}\end{array}$ & & $\mathbf{n = 5 4}$ & \\
\hline Sebentar & 8 & 13 & $21(39 \%)$ & 0,75 \\
Lama & 14 & 19 & $33(61 \%)$ & \\
\hline
\end{tabular}

Keterangan: chi square SPSS

Tabel 3 Hubungan Posisi Mengetik Komputer dengan Gejala CTS

\begin{tabular}{lcccc}
\hline \multirow{2}{*}{ Posisi Mengetik } & \multicolumn{2}{c}{ Gejala CTS } & \multirow{2}{*}{ Total } & p \\
\cline { 2 - 3 } & Tidak Ada Gejala & Ada Gejala & & \\
n=22 & 19 & $\mathbf{n = 3 2}$ & $\mathbf{n = 5 4}$ & 0,08 \\
\hline Senar & 3 & $\mathbf{2 1}$ & $40(74 \%)$ & $14(26 \%)$ \\
\hline
\end{tabular}

Keterangan: Uji Eksak Fisher

Pada penelitian ini sebagian besar responden mempunyai gejala CTS. Hasil penelitian ini sesuai dengan hasil penelitian Ali dan Sathiyasekaran ${ }^{12}$ yang menyatakan bahwa sebagian besar responden memiliki gejala CTS yang didukung oleh beberapa faktor, yaitu posisi mengetik komputer, indeks massa tubuh yang tidak normal, dan jenis kelamin. ${ }^{12}$

Hasil penelitian ini menunjukkan sebagian besar responden mempunyai durasi mengetik komputer lama bila dibanding dengan responden yang memiliki durasi mengetik komputer yang sebentar. Hasil ini sesuai dengan penelitian Newington dkk. ${ }^{13}$ bahwa sebagian besar responden penelitian memiliki durasi mengetik komputer lama. Hal ini dapat disebabkan oleh beban kerja dan jam operasional kerja yang terbatas sehingga durasi mengetik komputer lebih lama untuk menyelesaikan pekerjaannya. American Medical Association yang menyimpulkan bahwa durasi mengetik komputer tidak berhubungan dengan gejala CTS karena didapatkan hanya 5\% pekerja yang mengalami gejala CTS dari 5.600 pekerja perusahaan yang menggunakan komputer. ${ }^{14}$

Hasil penelitian ini menunjukkan sebagian besar responden memiliki posisi mengetik komputer yang benar sesuai dengan penelitian Alidan Sathiyasekaran. ${ }^{12}$ Para pekerja sudah memiliki pengetahuan mengenai posisi mengetik komputer yang benar, tetapi belum merata dan belum terdapat sosialisasi tentang posisi mengetik komputer yang benar di lingkungan kerja.

Hasil tersebut kemungkinan dapat disebabkan oleh masa kerja dan aktivitas fisik pada setiap responden yang bervariasi yang tidak dianalisis oleh peneliti karena keterbatasan penelitian.

Ali dan Sathiyasekaran ${ }^{12}$ juga telah menunjukkan terdapat hubungan antara masa kerja dan gejala CTS. Keadaan ini disebabkan oleh pajanan beban pekerjaan yang diterima oleh tangan dan jari pekerja. Pekerjaan dengan menggunakan komputer dalam durasi yang lama memberikan tekanan kepada jari dan pergelangan tangan.

Penelitian Stevents dkk. ${ }^{15}$ juga menyatakan bahwa pekerjaan dengan gerakan repetitive dengan durasi lama berisiko lebih tinggi mengalami CTS. Hal ini dapat disebabkan oleh penentuan durasi mengetik komputer waktu lama yang berbeda jangka waktunya.

Keadaan tersebut sesuai dengan penelitian yang menyatakan bahwa terdapat hubungan yang bermakna antara posisi tangan dan gejala CTS. ${ }^{16}$ Banyak bukti epidemiologi yang menjelaskan bahwa faktor fisiko seperti gerakan berulang, gaya, posisi tangan yang salah, dan vibrasi saat bekerja berhubungan dengan kejadian CTS. ${ }^{16}$ Bekerja dengan posisi salah meningkatkan jumlah energi yang dibutuhkan untuk bekerja. Apabila faktor risiko tersebut berlangsung lama maka dampaknya adalah penurunan kemampuan tubuh dan dapat menyebabkan kesakitan pada anggota tubuh yang juga dapat menjadi awal terjadi CTS bila terus dibiasakan. ${ }^{17}$

Kasus CTS lebih sering terjadi pada pekerja yang mempertahankan suatu postur lebih sering selama waktu kerja yang dapat menyebabkan suplai darah berkurang, akumulasi asam laktat, inflamasi, tekanan pada otot, dan trauma mekanis. Akibat beban kerja yang terus menerus tanpa memperoleh kesempatan untuk relaksasi membuat saraf medianus akan tertekan di antara terowongan karpal yang menurunkan fungsi saraf tersebut dan dapat menurunkan kesehatan pada pekerja, memengaruhi kinerja kerja pekerja, dan secara tidak langsung akan berdampak pada produktivitas tempat kerja. ${ }^{18}$

\section{Simpulan}

Simpulan dari penelitian ini adalah durasi mengetik komputer pada karyawan Unisba sebagian besar memiliki durasi yang lama dengan posisi mengetik yang benar. Terdapat hubungan posisi mengetik komputer dengan gejala CTS. 


\section{Ucapan Terima Kasih}

Terima kasih kepada seluruh karyawan Universitas Islam Bandung sebagai responden penelitian

\section{Daftar Pustaka}

1. International Labour Organization. Keselamatan dan kesehatan kerja [Internet]. 2013 [diunduh 1 Agustus 2018]. Tersedia dari: https//:www.ilo.org

2. Nurhikmah.2011. Faktor-faktoryangberhubungan dengan muskuloskeletal disorders (MSDs) pada pekerja bagian furnitur di Kecamatan Benda Kota Tangerang Tahun 2011 [Skripsi Ilmiah]. Jakarta: Universitas Islam Negeri Syarif Hidayatullah Jakarta.

3. Budiono AMS, Jusuf RMS, Pusparini A. Bunga rampai hiperkes dan keselamatan kerja. Edisi ke-2. Semarang: Badan Penerbit Universitas Diponegoro; 2003.

4. Ropper AH, Klein JP, Samuels MA. Adams and victor's-principle of neurology. Edisi ke-10. Boston: Mc Graw Hill Education; 2014.

5. Tanaka S, Wild DK, Seligman PJ, Halperin WE, Behrens VJ, Putz-Anderson V. Prevalence and work-relatedness of self-reported carpal tunnel syndrome among U.S. workers: analysis of the Occupational Health Supplement data of 1988 National Health Interview Survey. Am J Ind Med [Internet]. 2005 Apr [diunduh 4 Januari 2018];27(4):451-70. Tersedia dari: http://www. ncbi.nlm.nih.gov/pubmed/7793419

6. National Institutes of Occupational Safety and Health. Chapter 5: hand/wrist musculoskeletal disorders (carpal tunnel syndrome, hand/wrist tendinitis, and hand-arm vibration syndrome): Evidence for work-relatedness. NIOSH Publ No 97-141. 1997;(3):1-130.

7. Williams R, Westmorland M. Occupational cumulative trauma disorders of the upper extremity. Am J Occup Ther [Internet]. May 1 [diunduh 4 Januari 2018];48(5):411-20.
Tersedia dari: http://ajot.aota.org/Article. aspx?doi=10.5014/ajot.48.5.411

8. Tana L, Suharyanto H, Delima, Woro R. Carpal tunnel syndrome pada pekerja garmen di Jakarta. J Peneliti Kesehatan. 2004;32(2):73-82.

9. Barr AE, Barbe MF, Clark BD. Work-related musculoskeletal disorders of the hand and wrist: epidemiology, pathophysiology, and sensorimotor changes. J Orthop Sports Phys Ther [Internet]. 2004 Oct [diunduh 4 Januari 2018]. 2004;34(10):610-27. Tersedia dari: http:// www.ncbi.nlm.nih.gov/pubmed/15552707

10. Figure L. Boston carpal tunnel syndrome questionnaire (BCTQ). Advances. 2005;c:1-7.

11. Atroshi I, Gummesson C, Johnsson R, Ornstein E, Ranstam J, Rosén I, dkk. Prevalence of carpal tunnel syndrome in a general population. JAMA [serial on Internet]. 2009 Jul 14 [diunduh 9 February 2016];282(2):153-8. Tersedia dari; http://www.ncbi.nlm.nih.gov/pubmed/10411196

12. Ali KM, Sathiyasekaran BWC. Computer professionals and carpal tunnel syndrome (cts). Int J Occup Saf Ergon. 2006;12(3):319-25.

13. Newington L, Harris EC, Walker-Bone K. Carpal tunnel syndrome and work. Best Pract Res Clin Rheumatol [Internet]. 2015 Jun [diunduh 6 Februari 2018];29(3):440-53. Tersedia dari: http://www.ncbi.nlm.nih.gov/pubmed/26612240

14. Andersen J, Olney R. Typing rarely cause of carpal tunnel. J Am Med Assoc. 2013; 1. volume.

15. Stevens JC, Witt JC, Smith BE, Weaver AL The frequency of carpal tunnel syndrome in computer users at medical facility. Neurology. 2011;56:1568-70.

16. Aroori S, Spence, RAJ. Carpal tunnel syndrome. Ulster Med J. 2008 Jan; 77(1):6-17.

17. Tarwaka, Bakri SHA, Sudiajeng L. Ergonomi untuk k3 dan produktivitas. Edisi ke-1. Cetakan 1. Surakarta:Uniba Press; 2004.

18. Yagev Y, Gringolds M, Karakis I, Carel RS. Carpal tunnel syndrome: under-recognition of occupational risk factors by clinicians. Ind Health. 2007;45(6):820-2. 